\title{
Models for droplet heating and evaporation: an application to biodiesel, diesel and gasoline fuels
}

\section{Mansour Al Qubeissi*}

School of Mechanical, Aerospace and Automotive Engineering,

Faculty of Engineering, Environment and Computing,

Coventry University,

Coventry CV1 5FB, UK

Email: mansour.alqubeissi@coventry.ac.uk

*Corresponding author

\section{Sergei S. Sazhin}

Centre for Automotive Engineering (CAE),

School of Computing, Engineering and Mathematics,

University of Brighton,

Brighton BN2 4GJ, UK

Email: s.sazhin@brighton.ac.uk

\begin{abstract}
This paper presents our recent progress in the modelling of automotive fuel droplet heating and evaporation processes in conditions close to those in direct-injection internal-combustion engines. Three types of automotive-fuels are considered: biodiesel, diesel and gasoline fuels. Modelling of biodiesel fuel droplets is based on the application of the discrete component (DC) model. A distinctive feature of this model is that it is based on the analytical solutions to the transient heat conduction and species diffusion equations in the liquid phase, taking into account the effects of recirculation. The application of the DC model to fossil fuels (containing potentially hundreds of components), however, is computationally expensive. The modelling of these fuels is based on the recently introduced multi-dimensional quasi-discrete (MDQD) model. This model replaces a large number of components in diesel and gasoline fuels with a much smaller number of quasi-components/components without losing the main features of the original DC model. The MDQD model is shown to accurately predict droplet temperatures and evaporation times and to be much more computationally efficient than the DC model. The main features of these models and their applications to three types of automotive fuel droplets are summarised and discussed.
\end{abstract}

Keywords: automotive fuel; biodiesel; diesel; droplet; evaporation; gasoline; multi-component; heating.

Reference to this paper should be made as follows: Al Qubeissi, M. and Sazhin, S.S. (2017) 'Models for droplet heating and evaporation: an application to biodiesel, diesel and gasoline fuels', Int. J. Engineering Systems Modelling and Simulation, Vol. 9, No. 1, pp.32-40.

Biographical notes: Mansour Al Qubeissi is a Lecturer in Fluid Dynamics at the University of Coventry. He is sole author of the textbooks Heating and Evaporation of Multi-component Fuel Droplets and Development of a Conjugate Heat Transfer Solver; a designated reviewer of the International Conference on the Finite Volume Method: Applications AND Numerics (ICFVM 2016) and several IEEE proceedings; and an editorial board member of the World Academy of Science, Engineering and Technology (WASET), Laboratoire de Recherche en Hydraulique Souterraine et de Surface (LARHYSS), and the International Journal of Mechanical Engineering and Automation (IJMEA).

Sergei S. Sazhin is a Professor of Thermal Physics at the University of Brighton (UK). He received his PhD (Physics and Mathematics) at St Petersburg State University (Russia) in 1977; has been a fellow of the Institute of Physics, a Chartered Physicist, a research worker at the Institute of Physics, St. Petersburg State University, Russia (1972-1982), a research fellow, Department of Physics, Sheffield University, UK (1988-1992) and a Research Scientist at the Fluent Europe Ltd, Computational Fluid Dynamics Software and Consultancy Services, Sheffield, UK (1992-1996). Since 1996, he has been researching the modelling of fluid dynamics, heat transfer and combustion processes in sprays in internal combustion engines at the University of Brighton. 
This paper is a revised and expanded version of a paper entitled 'Modelling of droplet heating and evaporation: an application to biodiesel, gasoline and diesel fuels' presented at the 8th International Conference on 'Thermal Engineering Theory and Applications' (ICTEA 2015), Amman, Jordan, 28-21 May 2015.

\section{Introduction}

Studies on the heating and evaporation processes of automotive fuel droplets are crucial to the design of internal combustion engines and ensuring their good performance (Sazhin, 2014; Sirignano, 1999; Sazhina et al., 2000). Previous studies on these processes have been either based on the analysis of individual components, the discrete component (DC) model (Abianeh and Chen, 2012; Depredurand, 2009; Ra and Reitz, 2009), or on the probabilistic analysis of a large number of components [the continuous thermodynamics (Zhu and Reitz, 2002; Laurent et al., 2009; Grote et al., 2010) and the distillation curve (Burger et al., 2003; Smith and Bruno, 2006; Aleiferis and van Romunde, 2013) models]. In the first approach, the DC model is generally applicable to cases when relatively small numbers of components need to be taken into account. In the second approach a number of additional simplifying assumptions have been used, including the assumption that species inside droplets mix infinitely quickly [infinite diffusivity (ID) model]. In addition, the temperature gradients inside droplets have been ignored in most cases by assuming that the liquid thermal conductivity is infinitely large [infinite thermal conductivity (ITC) model]. On many occasions multi-component automotive fuels have been approximated by single components, using the single component (SC) model [e.g., n-dodecane has been used to represent diesel fuel (Sazhin et al., 2007a, 2014a, 2014b) and iso-octane has been used to represent gasoline fuel (Ma et al., 2014; Sazhin et al., 2007b)]. Also, recirculation due to relative droplet and gas velocities has been ignored in many cases.

A version of the DC model based on the analytical solutions to the heat transfer and species diffusion equations has been considered in Sazhin (2006), Sazhin et al. (2014c) and Al Qubeissi et al. (2013, 2015a, 2015b). Direct applications of this model have been limited to the case when the number of components in fuels is relatively small (e.g., biodiesel fuels). In the case of fossil fuels (containing potentially hundreds of components), however, the DC model is computationally very expensive when directly applied to modelling droplet heating and evaporation. In response to this problem, the multi-dimensional quasi-discrete (MDQD) model has been developed (Sazhin et al., 2014d). In this model, a large number of components in realistic automotive fuels is replaced with a small number of quasi-components/components, taking into account the same effects as considered in the DC model. This model has been shown to accurately predict the temperature of droplets and their evaporation times and to be computationally efficient (see Sazhin et al., 2014d, 2014e; Al Qubeissi et al., 2014, 2015c).
In this paper the above-mentioned models are briefly described and some results of their application to automotive fuel droplets in typical engine-like conditions are summarised. Descriptions of the models and input parameters are presented in Section 2. In Section 3, the results of the application of the DC model to the analysis of heating and evaporation of biodiesel fuel droplets are described. Section 4 focuses on the application of the MDQD model to commercial diesel fuel droplets. Section 5 presents the application of the MDQD model to typical gasoline fuel droplets. The main results of the paper are summarised in Section 6.

\section{Models and input parameters}

As in Sazhin (2006), Sazhin et al. (2014c, 2014e) and Al Qubeissi et al. (2014, 2015a, 2015b, 2015c) the analyses are based on the assumption that droplets are spherically symmetric, and temperature gradients, species diffusions and the effect of internal recirculation due to relative velocity between ambient gas and droplets are all accounted for using the effective thermal conductivity and effective diffusivity (ETC/ED) models. Additionally, the liquid diffusion coefficients for all species are assumed to be the same. The analytical solutions to the heat transfer and species diffusion equations are used in the analysis. The model based on the above-mentioned assumptions is referred to as the DC model. This model will be applied to the analysis of biodiesel fuel droplets.

As mentioned in Section 1, diesel and gasoline fuel droplets can include large numbers of components (up to one hundred and sometimes more), which fall into several groups according to their molecular structure. In this case, application of the DC model to such droplets is computationally expensive. As an alternative to the DC model, the MDQD model has been applied for the analyses of heating and evaporation of diesel and gasoline fuel droplets. In the MDQD model, the components with close carbon numbers within each individual group are merged together to form quasi-components. For each group $m$ the values of the average carbon number of quasi-components, $\bar{n}_{j m}$, have been introduced as (Sazhin et al., 2014d, 2014e; Al Qubeissi et al., 2014, 2015c): 


$$
\begin{aligned}
& \bar{n}_{1 m}=\frac{\sum_{n=n_{1 m}}^{n=n_{\left(\varphi_{m}+1\right)}}\left(n X_{n m}\right)}{\sum_{n=n_{1 m}}^{n=n_{(\varphi m+1)}} X_{n m}}, \\
& \bar{n}_{2 m}=\frac{\sum_{n=n_{\left(\varphi_{m}+2\right)}}^{n=n_{(2 \varphi m+2)}}\left(n X_{n m}\right)}{\sum_{n=n_{\left(\varphi_{m}+2\right)}}^{n=n_{\left(2 \varphi_{m}+2\right)}} X_{n m}} \\
& \bar{n}_{3 m}=\frac{\sum_{n=n_{(2 \varphi m+3)}}^{n=n_{(3 \varphi m+3)}}\left(n X_{n m}\right)}{\sum_{\left.n=n_{(2 \varphi m}+3\right)}^{\left.n=n_{(3 \varphi m}+3\right)} X_{n m}}, \\
& \bar{n}_{\ell m}=\frac{\sum_{n=n_{((\ell-1) \varphi m+\ell)}}^{n=n_{k_{m}}}\left(n X_{n m}\right)}{\sum_{n=n_{\left.(\ell-1) \varphi_{m}+\ell\right)}}^{n=n_{k_{m}}} X_{n m}},
\end{aligned}
$$

where $n_{1 m}=n_{m(\min )}$ is the minimal value of $n$ for which $X_{n m} \neq 0, n_{k_{m}}=n_{m(\max )}$ is the maximal value of $n$ for which $X_{n m} \neq 0$ (see Table 3 for gasoline fuel droplets), $\ell=$ integer $\left(\left(k_{m}+\varphi_{m}\right) /\left(\varphi_{m}+1\right)\right)$. Parameter $\varphi_{m}$ is assumed to be integer; $\varphi_{m}+1$ is equal to the number of components to be included in quasi-components, except possibly the last one in the group. $\varphi_{m}$ is assumed to be the same for all quasi-components within group $m$. If $\varphi_{m}=0$ then $\ell=k_{m}$ and the number of quasi-components is equal to the number of actual components (in this case the MDQD model reduces to the DC model). $\varphi_{m}$ and $k_{m}$ depend on $m$ in the general case.

This approach to generation of quasi-components is based on the selection of a number of components within each group forming a quasi-component $\left(\varphi_{m}+1\right)$. The number of components within each quasi-component, except possibly the last one, $\left(n_{c}\right)$ is taken equal to the nearest integer of the ratio $k_{m} / n_{q}$, where $n_{q}=\ell$ is the number of quasi-components. If $k_{m} / n_{q}$ is not an integer then the number of components in the last quasi-component $\left(n_{l c}\right)$ is either greater than $n_{c}$, if $\left(k_{m} / n_{q}\right)>n_{c}$, or less than $n_{c}$, if $\left(k_{m} / n_{q}\right) \leq n_{c}$. The molar fractions of these quasi-components/components are estimated as (Sazhin et al., 2014d):

$$
\left.\begin{array}{l}
X_{1 m}=\sum_{n=n_{1 m}}^{n=n_{\left(\varphi_{m}+1\right)}} X_{n m}, \\
X_{2 m}=\sum_{n=n_{\left(\varphi_{m}+2\right)}}^{n=n_{(2 \varphi+2)}} X_{n m}, \\
\ldots \ldots \ldots \ldots \ldots \ldots \ldots \ldots \ldots \ldots \ldots \ldots \ldots \ldots \ldots \ldots \\
X_{\ell m}=\sum_{\left.n=n_{(\ell-1) \varphi m}+\ell\right)}^{n=n_{k m}} X_{n m} .
\end{array}\right\}
$$

The results predicted by the following models will be compared in our analysis:

1 the contributions of all components are taken into account using the DC and ETC/ED models (indicated as ME)

2 the contributions of all components are taken into account using the ITC/ID model (indicated as MI)
3 a combination of the ITC and SC models, in which the fuel is approximated by individual components (iso-octane, for gasoline fuel (indicated as IO), n-dodecane, for diesel fuel (indicated as ND), and the dominant components (by molar fractions) for biodiesel fuels (indicated as SI).

Note that the predictions of the ITC/ID model have been inferred from the same numerical code as used for the ETC/ED model but with substantially increased values of liquid thermal conductivities and species diffusivities; both were increased by a factor of 100 .

The discrepancies between the evaporation times predicted by all models in comparison to the ME model will be estimated as:

$$
\text { Error }=\left|\frac{t_{M E}-t_{\text {model }}}{t_{M E}}\right| \times 100 \% .
$$

Similarly, the errors in the estimation of droplet surface temperatures are calculated using the same formula (3) with $t$ replaced by temperature $T$.

The droplets, with radii and temperatures at the initial stage of evaporation of $R_{d}=12 \mu \mathrm{m}$ and $T_{d 0}=300 \mathrm{~K}$, respectively, are assumed to be moving in still air at $U_{d}=10$ $\mathrm{m} / \mathrm{s}$. In the case of biodiesel and diesel fuel droplets, ambient air pressure and temperature are assumed equal to $p_{g}=32$ bar and $T_{g}=700 \mathrm{~K}$, respectively. In the case of gasoline fuel droplets, ambient air pressure and temperature are assumed equal to $p_{g}=5$ bar and $T_{g}=550 \mathrm{~K}$, respectively. These conditions are based on the previously reported data (Sazhin et al., 2014c, 2014d; Al Qubeissi et al., 2015a, 2015b, 2015c, 2015d; Pitz et al., 2007; Sazhina et al., 1999; Kukkadapu et al., 2012; Elwardany and Sazhin, 2012).

\section{Biodiesel fuel droplets}

The analysis presented in this section is focused on the modelling of biodiesel fuel droplet heating and evaporation. The temperature gradients and species diffusions inside the droplet are taken into account based on the analytical solutions to heat transfer and species diffusion equations, which are incorporated into a numerical algorithm (see Al Qubeissi et al., 2013; Sazhin et al., 2014c). Unlike typical fossil fuels, such as gasoline and diesel fuels, which can potentially be composed of hundreds of components, biodiesel fuel is composed of a relatively small number (up to 16) of fatty acid methyl esters (Gerpen, 2005; Sanford et al., 2009; Knothe, 2010; Grabar et al., 2011). This allows us to analyse species diffusion inside droplets based on the DC model, in which the diffusion of species is described without any additional approximations.

The analyses and results of the modelling of biodiesel fuel droplet heating and evaporation, using the above-mentioned approach, were presented in Al Qubeissi et al. (2015a, 2015b) and Sazhin et al. (2014c). In the current paper, an analysis similar to the one presented in Sazhin et al. (2014c) is performed but for three of the most 
widely used types of biodiesel fuels: soybean methyl ester (SME), rapeseed methyl ester (RME) and palm kernel methyl ester (PMK), the compositions of which are described in Al Qubeissi et al. (2015a, 2015b), and using the engine conditions and parameters described in Section 2. The thermodynamic and transport properties of methyl esters are inferred from Al Qubeissi et al. (2015b) and Sazhin et al. (2014c).

The plots of the droplet surface temperatures $\left(T_{S}\right)$ and radii $\left(R_{d}\right)$ versus time, for these three types of biodiesel fuels, are presented in Figures 1 to 3 . The general trends of the curves shown in these figures are the same as presented in the previous case studies (see Al Qubeissi et al., 2013, 2015a, 2015b; Sazhin et al., 2014c), but the errors in droplet surface temperatures and evaporation times, predicted by the MI and SI models relative to those predicted by the ME model, were different from those described in our previous papers. The maximal errors for these surface temperatures and evaporation times for the results predicted by the MI and SI models relative to those predicted by the ME model are shown in Table 1.

Figure 1 The plots of time evolution of droplet surface temperatures $\left(T_{s}\right)$ and radii $\left(R_{d}\right)$ of an SME droplet as predicted by the multi-component ETC/ED model (ME), single-component (SC)/ITC model (SI), and multi-component ITC/ID model (MI)

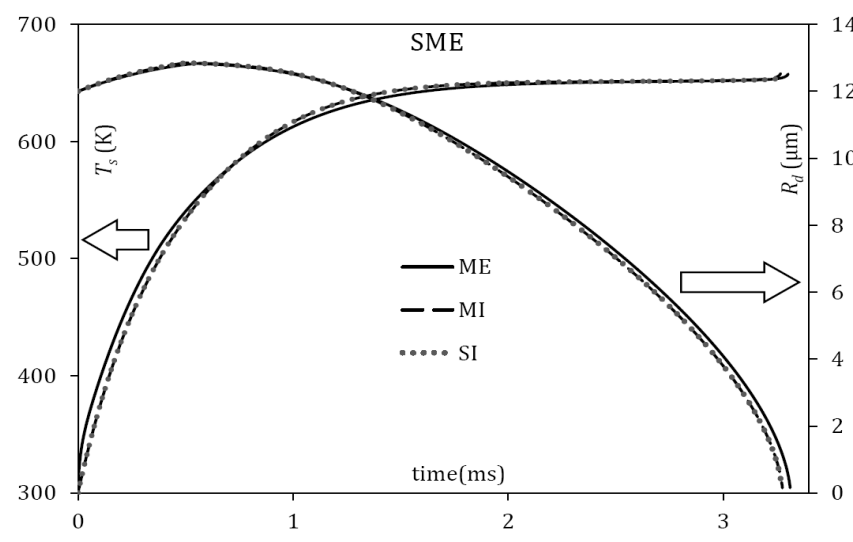

Note: The droplet is assumed to have initial radius $12 \mu \mathrm{m}$ and is moving at $10 \mathrm{~m} / \mathrm{s}$ in still air at temperature and pressure equal to $700 \mathrm{~K}$ and $30 \mathrm{bar}$ respectively.

Figure 2 The same as Figure 1 but for an RME droplet

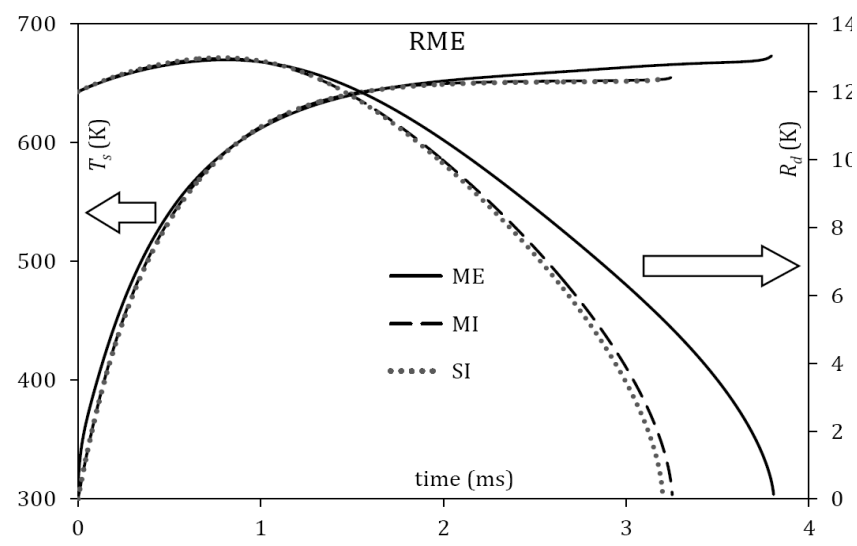

Figure 3 The same as Figures 1 and 2, but for a PMK droplet

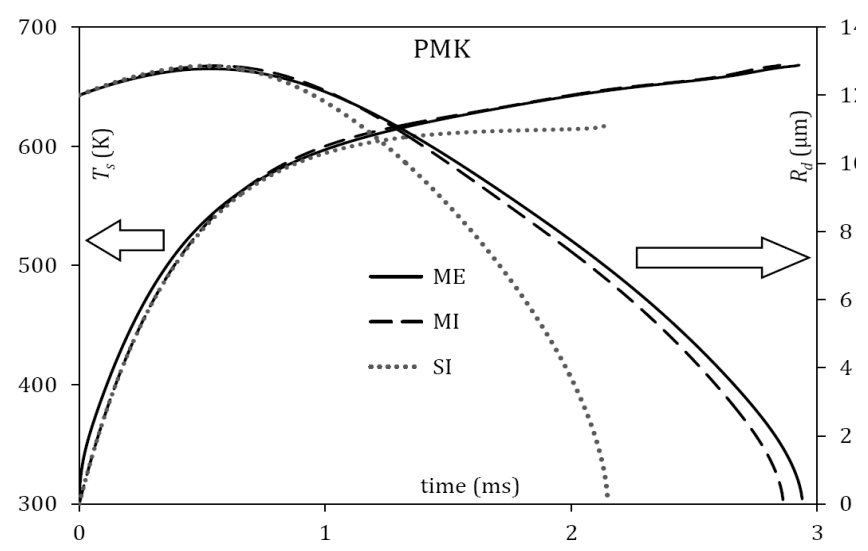

Table 1 The maximal errors of surface temperatures and evaporation times, predicted by the MI and SI models relative to those predicted by the ME model for SME, RME and PMK biodiesel fuels; these errors have been estimated based on expression (3)

\begin{tabular}{lcccc}
\hline Biodiesel & $T(M I)$ & $T(S I)$ & $t_{\text {evap }}(M I)$ & $t_{\text {evap }}(S I)$ \\
\hline SME & 7.9 & 7.9 & 1.1 & 1.2 \\
RME & 8.4 & 8.4 & 14.6 & 15.9 \\
PMK & 7.3 & 7.4 & 2.7 & 26.9 \\
\hline
\end{tabular}

As one can see from Table 1, the maximal errors in evaporation times predicted by the MI model are those for RME. These errors predicted by the SI model are maximal for PMK. In all cases the MI model gives more accurate results compared with the SI model and the evaporation times predicted by the MI and SI models are shorter than those predicted by the ME model. The maximal errors in predicted droplet surface temperatures are about the same for all models and all three biodiesel fuels and lie in the range $7.3 \%-8.4 \%$.

These discrepancies between the predictions of droplet surface temperatures and radii can be related to the fact that at the final stage of droplet evaporation the mass fractions of species with larger numbers of carbon atoms $n$ (e.g., C24:1 M and C22:1 M) increase at the expense of species with smaller $n$ (e.g., C16:0 M). At time instants close to the complete evaporation of droplets, mass fractions of all species except the heaviest component (C24:1 M) decrease with time. This is illustrated in Figure 4, where the time evolutions of surface mass fractions of four dominant species are presented. The species with larger $n$ tend to be less volatile and have higher wet bulb temperatures than the species with lower $n$. The results shown in Figure 4 are consistent with those shown in Figure 5, where the mass fractions of species as functions of the normalised distance from the centre of the droplet are shown. Plots similar to those shown in Figure 5 but for droplet temperatures are shown in Figure 6. Figures 5 and 6 clearly show the limitations of the ITC and ID models widely used for the modelling of droplet heating and evaporation. 
Figure 4 The plots of time evolution of surface mass fractions of C16:0M, C18:1M, C22:1M, C24:1M and C18:3M for an RME droplet under the same conditions as in Figures 1 to 3

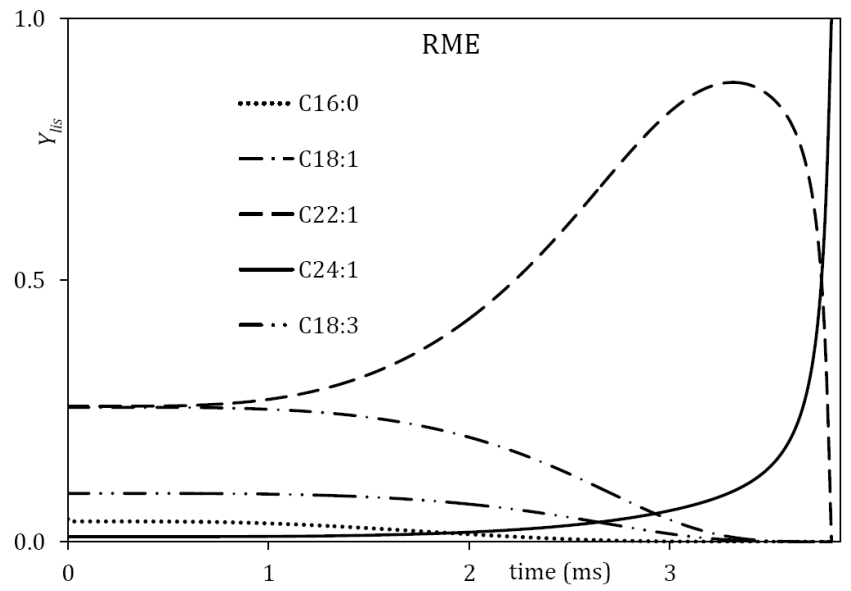

Figure 5 The plots of mass fractions of C16:0M, C18:1M, $\mathrm{C} 22: 1 \mathrm{M}, \mathrm{C} 24: 1 \mathrm{M}$ and $\mathrm{C} 18: 3 \mathrm{M}$ versus normalised distance from the centre of the droplet at three time instants, $0.02 \mathrm{~ms}, 1 \mathrm{~ms}$ and $1.5 \mathrm{~ms}$, for an RME droplet under the same conditions as in Figures 1 to 4

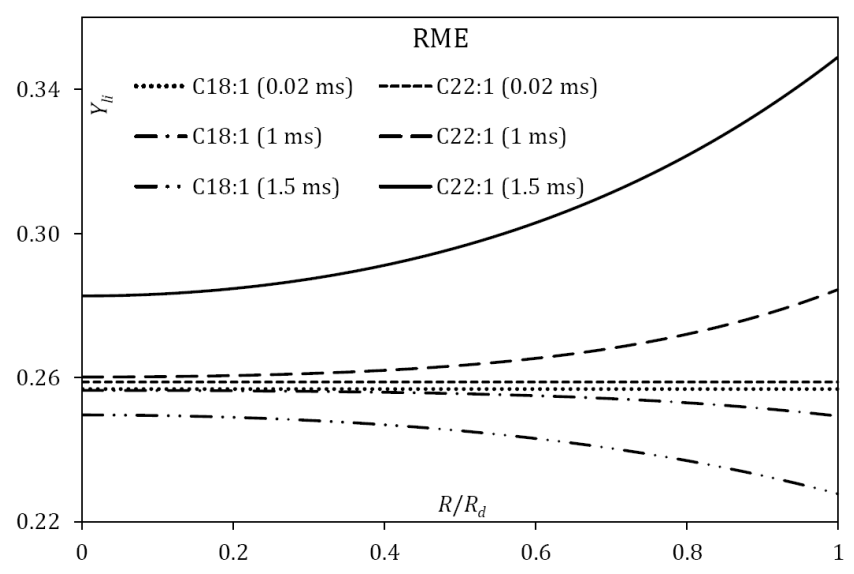

Figure 6 The plots of temperature versus normalised distance from the centre of the droplet at four time instants, 0.02 $\mathrm{ms}, 0.5 \mathrm{~ms}, 1 \mathrm{~ms}$ and $1.5 \mathrm{~ms}$, for an RME droplet under the same conditions as in Figures 1 to 5

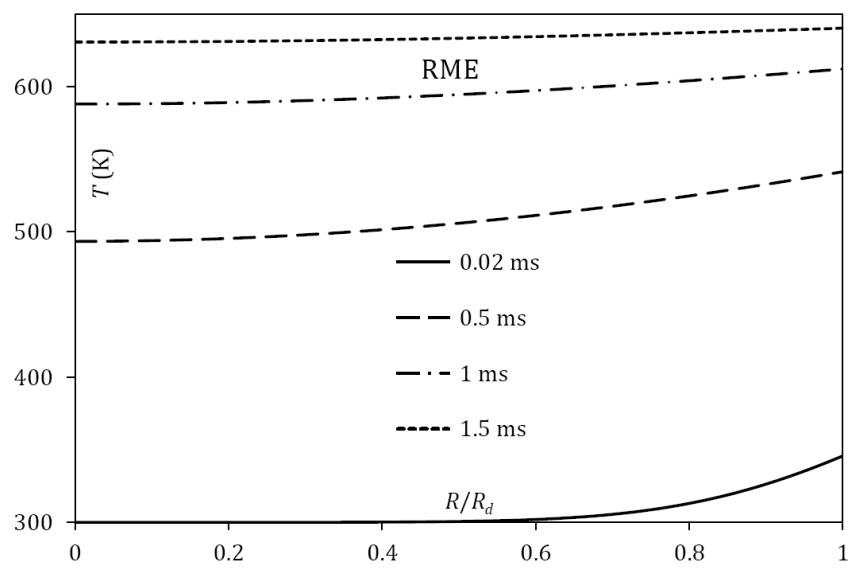

\section{Diesel fuel droplets}

As explained in Section 3, the main difficulty with modelling diesel fuel droplet heating and evaporation, compared with biodiesel fuel droplets, lies in the fact that diesel fuels contain many more (potentially over 100) components, compared with biodiesel fuels (up to 16 components). As mentioned earlier, the modelling of diesel fuel droplet heating and evaporation have been mainly based on the probabilistic analysis of a large number of components (e.g., the continuous thermodynamics or distillation curve models) and rely on a rather crude assumption that species inside droplets mix instantaneously. The application of the DC model to the modelling of diesel fuel droplets has been seen as a rather computationally expensive approach for practical engineering applications.

An alternative approach for taking into account the full composition of diesel fuel when modelling this fuel droplet heating and evaporation was introduced in Sazhin et al. (2014d). This approach is based on the 'MDQD' model described in Section 2. This model is used in our analysis.

The full composition of diesel fuel containing 98 components has been replaced with 12 and 15 quasi-components/components (QC/C) using the MDQD model. The performances of these two approximations are compared to the ones based on the ME (benchmark model), MI and ND (diesel fuel is approximated by n-dodecane) models. The $12 \mathrm{QC} / \mathrm{C}$ are formed of four alkane $\mathrm{QC}$, two cycloalkane QC, one bicycloalkane QC, two alkylbenzene $\mathrm{QC}$, one indane/tetraline QC, one naphthalene QC and one characteristic component of tricycloalkane (see Sazhin et al., 2014d for details), ignoring negligible contributions of other characteristic components (diaromatic and phenanthrene). The $15 \mathrm{QC} / \mathrm{C}$ are formed of four alkane $\mathrm{QC}$, three cycloalkane $\mathrm{QC}$, one bicycloalkane $\mathrm{QC}$, three alkylbenzene QC, two indane/tetraline QC, one naphthalene QC and one characteristic component of tricycloalkane (see Sazhin et al., 2014d for details), ignoring negligible contributions of other characteristic components (diaromatic and phenanthrene).

The molar fractions of QC/C are described by the matrix $X_{n m}$ [system (2)], where $n$ refers to the number of carbon atoms, and $m$ refers to the groups (e.g., cycloalkanes) or individual components (tricycloalkane, diaromatic and phenanthrene). The maximal number of non-zero components in matrix $X_{n m}$ is 98 . The link between the values of $m$ and the groups of components is shown in Table 2.

The time evolution of diesel fuel droplet surface temperatures $\left(T_{s}\right)$ and radii $\left(R_{d}\right)$ is presented in Figure 7 . The plots are presented for six cases: the contributions of all components are taken into account using the effective thermal conductivity/effective diffusivity (ETC/ED) model (indicated as $\mathrm{ME}$ ); the contributions of all components are taken into account using the infinite thermal conductivity/infinite diffusivity (ITC/ID) model (indicated as $\mathrm{MI}$ ); the composition of diesel fuel is approximated by 15 and $12 \mathrm{QC} / \mathrm{C}$ using the MDQD model (indicated as 15 and 12 respectively); and diesel fuel composition is 
approximated by n-dodecane using the ITC model (indicated as ND).

Table 2 The relation between parameter $m$ and groups of components in diesel fuel

\begin{tabular}{lc}
\hline$m$ & Component \\
\hline 1 & Alkanes \\
2 & Cycloalkanes \\
3 & Bicycloalkanes \\
4 & Alkylbenzenes \\
5 & Indanes/tetralines \\
6 & Naphthalenes \\
7 & Tricycloalkane \\
8 & Diaromatic \\
9 & Phenanthrene \\
\hline
\end{tabular}

Figure 7 The plots of time evolution of droplet surface temperatures $\left(T_{s}\right)$ and radii $\left(R_{d}\right)$ of a diesel fuel droplet as predicted by five approaches: the contributions of all components are taken into account using the ETC/ED model (indicated as ME); the contributions of all components are taken into account using the ITC/ID model (indicated as $\mathrm{MI}$ ); diesel composition is replaced by $\mathrm{n}$-dodecane using the ITC model (indicated as ND); the composition of diesel fuel is approximated by 15 and $12 \mathrm{QC} / \mathrm{C}$ using the MDQD model (indicated as 15 and 12 respectively), under the same conditions as in Figures 1 to 6

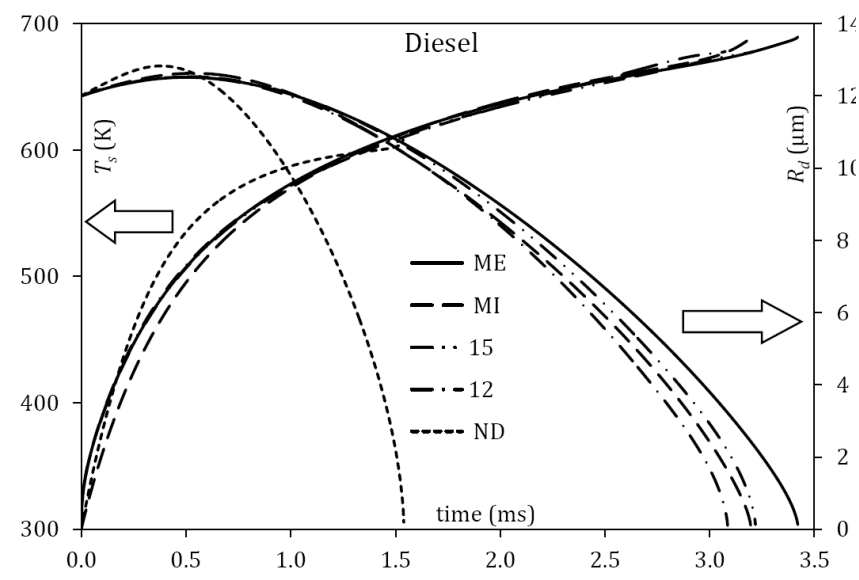

As can be seen from Figure 7, the predictions of diesel fuel droplet evaporation time ( $\left.t_{\text {evap }}\right)$ and $T_{s}$ using the MI model underestimate $t_{\text {evap }}$ by about $7 \%$ and $T_{s}$ by up to $9 \%$, compared to the same values predicted by the ME model. Similarly, the ND model underestimates $t_{\text {evap }}$ and $T_{s}$ by about $55 \%$ and up to $7 \%$, respectively, compared to the values predicted by the ME model. At the same time, the approximation of diesel fuel composition (98 components) with $12 \mathrm{QC} / \mathrm{C}$, using the MDQD model, underestimates $t_{\text {evap }}$ and $T_{s}$ by less than $10 \%$ and up to $1 \%$, respectively, compared to the values predicted by the ME model. Also, the approximation of diesel fuel composition with $15 \mathrm{QC} / \mathrm{C}$, using the MDQD model, underestimates $t_{\text {evap }}$ and $T_{s}$ by less than $6 \%$ and up to $0.4 \%$, respectively, compared to the values predicted by the ME model. The reduction of the full composition of diesel fuel (98 components) to $15 \mathrm{QC} / \mathrm{C}$ can make a significant contribution to computational efficiency, with a possible reduction in CPU time by $84 \%$ compared to the case when the ME model is used (Sazhin et al., 2014d; Al Qubeissi et al., 2014), when up to 6\% error in the accuracy of predicting droplet evaporation time can be tolerated.

Although the results predicted by the MI model indicate a reasonably close agreement with the ones predicted by the ME model for this particular case, this model cannot adequately describe the underlying physics of the processes inside droplets (heat conduction and species diffusion). Hence, it can lead to more noticeable errors under different conditions or for a broader range of case studies (see Sazhin et al., 2014d). This was clearly shown in the case of biodiesel fuel droplets (see Figures 1 to 3 and Table 1) in Section 3.

As in the case of biodiesel fuel droplets, the changes in the behaviour of the droplet radii when using different models are related to the fact that at the final stages of droplet evaporation the mass fractions of species with larger numbers of carbon atoms $n$ at the surface of the droplets increase at the expense of the species with smaller $n$ (cf., Figures 4 to 6). This behaviour is attributed to the contribution of the species diffusion within the droplets. Heat conduction and recirculation inside droplets contribute to the time evolution of droplet surface temperature.

\section{Gasoline fuel droplets}

In this section, the results of the application of the MDQD model (described in Section 2) to the analysis of gasoline fuel droplet heating and evaporation are described. As in Al Qubeissi et al. (2015c), the contributions of the two groups of alkanes, n-alkanes (n-paraffin) and iso-alkanes (isoparaffin), are considered separately, taking into account the differences in their thermodynamic and transport properties.

An analysis similar to the one presented in Al Qubeissi et al. $(2015 \mathrm{c}, 2015 \mathrm{e})$ is performed but under different engine-like conditions. The composition of gasoline fuel (FACE C) and its thermodynamic and transport properties are inferred from Al Qubeissi et al. (2015c) and Sarathy et al. (2015). As in Al Qubeissi et al. (2015c), the undefined species are ignored and the species with the same chemical formulae and very close thermodynamic and transport properties are merged to form representative components. This has led to the reduction of the original 83 components (see Sarathy et al., 2015), to 20 components. As in the case of diesel fuel (see Section 4), the components with similar molecular structures formed separate groups as shown in Table 3. 
Table 3 The relation between parameter $m$ and groups of gasoline fuel

\begin{tabular}{lc}
\hline$m$ & Component \\
\hline 1 & n-alkanes \\
2 & Iso-alkanes \\
3 & Aromatics \\
4 & Indanes/naphthalenes \\
5 & Cycloalkanes \\
6 & Olefins \\
\hline
\end{tabular}

The plots of the droplet surface temperatures $\left(T_{s}\right)$ and radii $\left(R_{d}\right)$ versus time, using four approaches to modelling gasoline fuel droplet heating and evaporation, are presented in Figure 8.

Figure 8 The plots of time evolution of droplet surface temperatures $\left(T_{s}\right)$ and radii $\left(R_{d}\right)$ of a gasoline fuel droplet as predicted by four approaches: the contributions of all components are taken into account using the ETC/ED model (indicated as ME); the contributions of all components are taken into account using the ITC/ID model (indicated as MI); the composition of gasoline fuel is replaced with isooctane using the ITC model (indicated as IO); the composition of gasoline fuel is approximated by six $\mathrm{QC} / \mathrm{C}$ using the MDQD model (indicated as 6)

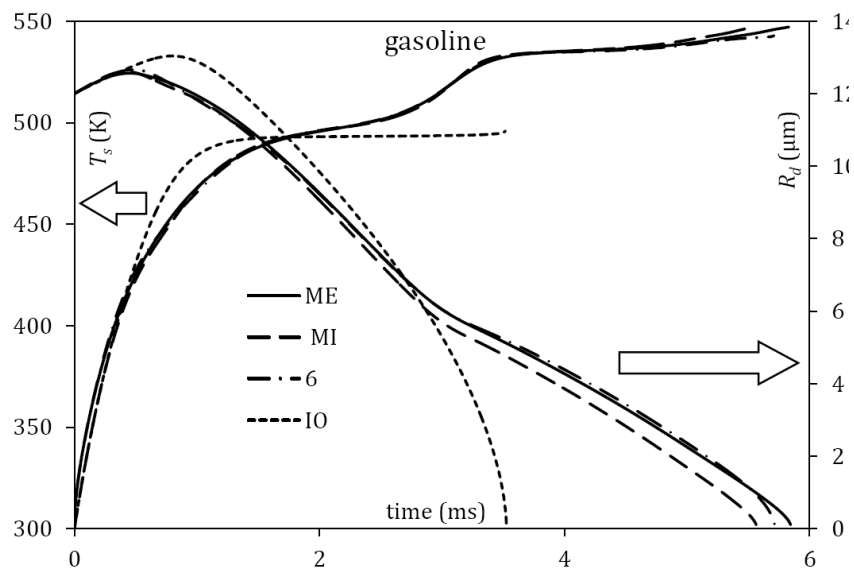

Note: Gas temperature and pressure are assumed equal to $550 \mathrm{~K}$ and 10 bar respectively.

As can be seen from Figure 8, the predictions of gasoline fuel droplet evaporation time ( $\left.t_{\text {evap }}\right)$ and $T_{s}$ using the MI model underestimate the values of $t_{\text {evap }}$ and $T_{s}$ by about $5 \%$ and up to $4 \%$, respectively, compared to the values predicted by the ME model. The prediction of the IO model underestimates $t_{\text {evap }}$ and $T_{s}$ by about $40 \%$ and up to $7 \%$, respectively, compared to the values predicted by the $\mathrm{ME}$ model. At the same time, the approximation of 20 components of gasoline fuel with six QC/C using the MDQD model underestimates $t_{\text {evap }}$ and $T_{s}$ by only about $2 \%$ and up to $0.6 \%$, respectively, compared to the values predicted by the ME model. These trends are similar to the ones presented in Section 4 for diesel fuel droplets and in $\mathrm{Al}$ Qubeissi et al. (2015c) for the same fuel but with different input parameters. As in the case of biodiesel and diesel fuels, the differences in the predictions of different models are attributed to the fact that the mass fractions of heavier (less volatile) components increase at the expense of lighter (more volatile) components near the end of droplet evaporation.

The reduction of the full composition of gasoline fuel (20 components) to $6 \mathrm{QC} / \mathrm{C}$ can make a significant contribution to computational efficiency, with up to $70 \%$ reduction in CPU time (see Al Qubeissi et al., 2015c for details), when up to $2 \%$ error in the accuracy of predicted droplet evaporation time can be accepted.

\section{Conclusions}

The modelling of heating and evaporation of three types of automotive-fuel droplets has been considered; these are biodiesel, diesel and gasoline. Modelling of biodiesel fuel droplets has been based on the application of the DC model. In the cases of diesel and gasoline fuel droplets, the recently developed MDQD model has been found to be suitable for the analysis of fuel droplet heating and evaporation, based on a compromise between accuracy and CPU efficiency.

In agreement with the previous findings, it has been shown that ignoring the effects of species diffusion, temperature gradient and recirculation inside droplets, or assuming that these species can be replaced by a single component, which are common practices when modelling the heating and evaporation of fuel droplets in many engineering applications, can lead to noticeable errors in the predictions of the droplet surface temperatures and evaporation times of all droplets studied. In the case of biodiesel fuel droplets, it is recommended that the ETC/ED model, taking into account diffusion of all species, is used for the analysis of these processes.

It is pointed out that the approximation of the automotive fuels under consideration, assuming that species mix infinitely quickly or do not mix at all, leads to underestimation of droplet evaporation time with errors up to $27 \%$, for biodiesel, $55 \%$, for diesel, and $40 \%$, for gasoline fuel, which are not acceptable in most engineering applications.

The main problem with the application of the DC model to the analysis of realistic diesel and gasoline fuel droplet heating and evaporation lies in the fact that it is computationally expensive. It has been shown that the most efficient (from the point of view of accuracy and CPU efficiency) model for analysing diesel and gasoline fuel droplet heating and evaporation is the recently introduced MDQD model. It has been shown that the approximation of 98 components of diesel fuel by 15 quasicomponents/components leads to under-prediction of the droplet evaporation time by less than 6\%. Also, the approximation of 20 components of gasoline fuel by six quasi-components/components leads to under-prediction of the droplet evaporation time by about $2 \%$. These errors are believed to be acceptable in most engineering applications. 


\section{Acknowledgements}

The authors acknowledge the organisers of the 8th International Conference on 'Thermal Engineering Theory and Applications' (ICTEA 2015) for hosting the oral presentation of this work, and they are grateful to the EPSRC (Grant EP/J006793/1) for their financial support of the work on this project.

\section{References}

Abianeh, O.S. and Chen, C.P. (2012) 'A discrete multicomponent fuel evaporation model with liquid turbulence effects', International Journal of Heat and Mass Transfer, Vol. 55, Nos. 23-24, pp.6897-6907.

Al Qubeissi, M., Kolodnytska, R. and Sazhin, S.S. (2013) 'Biodiesel fuel droplets: modelling of heating and evaporation processes', in 25th European Conference on Liquid Atomization and Spray Systems, September, Vol. 4 (CD), Crete, Greece.

Al Qubeissi, M., Sazhin, S.S., de Sercey, G. and Crua, C. (2014) 'Multi-dimensional quasi-discrete model for the investigation of heating and evaporation of diesel fuel droplets', in 26th European Conference on Liquid Atomization and Spray Systems, Vol. ABS-135 (CD), Bremen, Germany, University of Bremen.

Al Qubeissi, M., Sazhin, S.S., Crua, C. and Heikal, M.R. (2015a) 'Modelling of heating and evaporation of biodiesel fuel droplets', International Journal of Mechanical, Aerospace, Industrial and Mechatronics Engineering, Vol. 9, No. 1, pp.46-49.

Al Qubeissi, M., Sazhin, S.S., Crua, C., Turner, J. and Heikal, M.R. (2015b) 'Modelling of biodiesel fuel droplet heating and evaporation: effects of fuel composition', Fuel, Vol. 154, pp.308-318.

Al Qubeissi, M., Sazhin, S.S., Turner, J., Begg, S., Crua, C. and Heikal, M.R. (2015c) 'Modelling of gasoline fuel droplets heating and evaporation', Fuel, Vol. 159, pp.373-384.

Al Qubeissi, M., Sazhin, S.S.,Crua, C. and Heikal, M.R. (2015d) 'Modelling of heating and evaporation of biodiesel fuel droplets', in ICHTA: XIII International Conference on Heat Transfer and Applications, World Academy of Science, Engineering and Technology (WASET), London, UK, January, Vol. 2, No. 9, p.667.

Al Qubeissi, M., Sazhin, S.S. and Heikal, M.R. (2015e) 'Modelling of droplet heating and evaporation: an application to biodiesel, gasoline and diesel fuels', in 8th International Conference on Thermal Engineering: Theory and Applications, May, Vol. 13 (CD), Ryerson University, Amman, Jordan,

Aleiferis, P.G. and van Romunde, Z.R. (2013) 'An analysis of spray development with iso-octane, n-pentane, gasoline, ethanol and n-butanol from a multi-hole injector under hot fuel conditions', Fuel, Vol. 105, pp.143-168.

Burger, M., Schmehl, R., Prommersberger, K., Schafer, O., Koch, R. and Wittig, S. (2003) 'Droplet evaporation modeling by the distillation curve model: accounting for kerosene fuel and elevated pressures', International Journal of Heat and Mass Transfer, Vol. 46, No. 23, pp.4403-4412.

Depredurand, V. (2009) Approche experimentale de l'evaporation de sprays de combustibles multicomposant, $\mathrm{PhD}$ thesis, Vandoeuvre-Les-Nancy, France.
Elwardany, A.E. and Sazhin, S.S. (2012) 'A quasi-discrete model for droplet heating and evaporation: application to diesel and gasoline fuels', Fuel, Vol. 97, pp.685-694.

Gerpen, J.V. (2005) 'Biodiesel processing and production', Fuel Processing Technology, Vol. 86, No. 10, pp.1097-1107.

Grabar, I.G., Kolodnytska, R.V. and Semenov, V.G. (2011) Biofuels based on Oil for Diesel Engines, ZDTU, Zhytomyr (in Ukrainian).

Grote, M., Lucka, K. and Khne, H. (2010) 'Multicomponent droplet evaporation of heating oil using a continuous thermodynamics model', in $V$ ECCOMAS CFD, Lisbon, Portugal.

Knothe, G. (2010) 'Biodiesel and renewable diesel: a comparison', Progress in Energy and Combustion Science, Vol. 36, No. 3, pp.364-373.

Kukkadapu, G., Kumar, K., Sung, Ch-J., Mehl, M. and Pitz, W.J. (2012) 'Experimental and surrogate modeling study of gasoline ignition in a rapid compression machine', Combustion and Flame, Vol. 159, No. 10, pp.3066-3078.

Laurent, C., Lavergne, G. and Villedieu, Ph. (2009) 'Continuous thermodynamics for droplet vaporization: comparison between gamma-PDF model and QMoM', Comptes Rendus Mcanique, Vol. 337, Nos. 6-7, pp.449-457.

Ma, X., Jiang, Ch., Xu, H., Ding, H. and Shuai, S. (2014) 'Laminar burning characteristics of 2-methylfuran and isooctane blend fuels', Fuel, Vol. 116, pp.281-291.

Pitz, W.J., Cernansky, N.P., Dryer, F.L., Egolfopoulos, F.N., Farrell, J.T., Friend, D.G. and Pitsch, H. (2007) Development of an Experimental Database and Chemical Kinetic Models for Surrogate Gasoline Fuels, SAE Technical Paper 2007-01-0175, SAE International, Warrendale, PA.

Ra, Y. and Reitz, R.D. (2009) 'A vaporization model for discrete multi-component fuel sprays', International Journal of Multiphase Flow, Vol. 35, No. 2, pp.101-117.

Sanford, S.D., White, J.M., Shah, P.S., Wee, C., Valverde, M.A. and Meier, G.R. (2009) Feed Stock and Biodiesel Characteristics Report, Technical report, Renewable Energy Group, Ames, Iowa, USA.

Sarathy, S.M., Kukkadapu, G., Mehl, M., Wang, W., Javed, T., Park, S., Oehlschlaeger, M.A., Farooq, A., Pitz, W.J. and Sung, Ch-J. (2015) 'Ignition of alkane-rich FACE gasoline fuels and their surrogate mixtures, Proceedings of the Combustion Institute, Vol. 35, No. 1, pp.249-257.

Sazhin, S.S. (2006) 'Advanced models of fuel droplet heating and evaporation', Progress in Energy and Combustion Science, Vol. 32, No. 2, pp.162-214.

Sazhin, S.S. (2014) Droplets and Sprays, Springer, London.

Sazhin, S.S., Al Qubeissi, M. and Xie, J-F. (2014a) 'Two approaches to modelling the heating of evaporating droplets', International Communications in Heat and Mass Transfer, Vol. 57, pp.353-356.

Sazhin, S.S., Shishkova, I.N. and Al Qubeissi, M. (2014b) 'Heating and evaporation of a two-component droplet: hydrodynamic and kinetic models', International Journal of Heat and Mass Transfer, Vol. 79, pp.704-712.

Sazhin, S.S., Al Qubeissi, M., Kolodnytska, R., Elwardany, A.E., Nasiri, R. and Heikal, M.R. (2014c) 'Modelling of biodiesel fuel droplet heating and evaporation', Fuel, Vol. 115, pp.559-572. 
Sazhin, S.S., Al Qubeissi, M., Nasiri, R., Gunko, V.M., Elwardany, A.E., Lemoine, F., Grisch, F. and Heikal, M.R. (2014d) 'A multi-dimensional quasi-discrete model for the analysis of Diesel fuel droplet heating and evaporation', Fuel, Vol. 129, pp.238-266.

Sazhin, S.S., Al Qubeissi, M. and Heikal, M.R. (2014e) 'Modelling of biodiesel and diesel fuel droplet heating and evaporation', in 15th International Heat Transfer Conference, Begell House, Kyoto, Japan, August, Vol. IHTC15-8936.

Sazhin, S.S., Shishkova, I.N., Kryukov, A.P., Levashov, V.Y. and Heikal, M.R. (2007a) 'Evaporation of droplets into a background gas: kinetic modelling', International Journal of Heat and Mass Transfer, Vol. 50, Nos. 13-14, pp.2675-2691.

Sazhin, S.S., Kristyadi, T., Abdelghaffar, W.A., Begg, S., Heikal, M.R., Mikhalovsky, S.V., Meikle, S.T. and Al-Hanbali, O. (2007b) 'Approximate analysis of thermal radiation absorption in fuel droplets', Journal of Heat Transfer, Vol. 129, No. 9, p.1246.
Sazhina, E.M., Sazhin, S.S., Heikal, M.R. and Marooney, C.J. (1999) 'The shell autoignition model: applications to gasoline and diesel fuels', Fuel, Vol. 78, No. 4, pp.389-401.

Sazhina, E.M., Sazhin, S.S., Heikal, M.R., Babushok, V.I. and Johns, R.J.R. (2000) 'A detailed modelling of the spray ignition process in diesel engines', Combustion Science and Technology, Vol. 160, No. 1, pp.317-344.

Sirignano, W.A. (1999) Fluid Dynamics and Transport of Droplets and Sprays, Cambridge University Press, Cambridge, UK.

Smith, B.L. and Bruno, T.J. (2006) 'Advanced distillation curve measurement with a model predictive temperature controller', International Journal of Thermophysics, Vol. 27, No. 5, pp.1419-1434.

Zhu, G-Sh. and Reitz, R.D. (2002) 'A model for high-pressure vaporization of droplets of complex liquid mixtures using continuous thermodynamics', International Journal of Heat and Mass Transfer, Vol. 45, No. 3, pp.495-507. 